\title{
MÚLTIPLES MORADAS
}

\section{Claudio Guillén}

(Barcelona: Tusquets, 1998, 484 páginas)

Claudio Guillén es un estudioso sólido y agudo que reelabora y reescribe en este libro once ensayos anteriores; en años pasados había editado entre nosotros tres volúmenes principales de los que mencionamos ahora El primer Siglo de Oro (1988) y Teorías de la historia literaria (1989): siempre hemos recordado como muy veraces e instructivos diferentes capítulos de uno y otro tomo, y en justicia histórica hay que decir que algunos de ellos resultaron en su día bien innovadores, lo que habrá de tenerse presente cuando se trace la trayectoria del análisis literario español de la segunda mitad de nuestro siglo.

Claudio Guillén - según decimos- es autor de escritos críticos de importancia y no sólo por lo que a la literatura comparada se refiere: su obra ha de tenerse presente junto a la de otros estudiosos más a los que de ordinario sí suele recordarse.

Múltiples moradas es un texto amplio y culto, que revela muchas sensibilidades en su autor: Guillén conoce, por supuesto, la literatura y las literaturas, pero también los escritos que pueden importarle en 
algún momento de José Ferrater Mora, o de Julián Marías, o de Carlos Castilla del Pino o de Fernando Savater... El volumen lleva al frente a modo de lema dos citas, una de las cuales es un poema de Jorge Guillén: «- ¿Tiene usted enemigos? / -Uno solo: / El que me simplifica», y en efecto el espíritu de todo el libro es el de «percibir [...] las convivencias que ocupan nuestras vidas», es decir, lo diverso, lo complejo de las situaciones de lo real -en este caso de las situaciones literarias-. Así se constituye en verdad en nuestro enemigo quien nos simplifica, y en el saber se constituye en enemigo de lo real (o sea, en inadecuado y falseador parcial y consciente $o$ inconsciente de las cosas) quien las simplifica.

Según decimos, Claudio Guillén alude a los distintos submundos circundantes sociales, políticos y culturales, y se pregunta: «¿Qué forma de pensamiento logra amoldarse a semejante complejidad?», para contestar entre otras con estas palabraș: «Al comparatista le corresponde preguntar lo que a otros les puede dejar sin cuidado, por ejemplo: este género poético, o esta forma, o este tema, ¿se circunscribe a la trayectoria de determinada lengua o es de uso universal?». Quizá la presente preocupación por la presencia en diferentes literaturas de unas mismas formas o temas resulta convergente con la preocupación en los mismos años en que nuestro autor escribe y en la linguiística norteamericana, por los universales del lenguaje: en definitiva se trataría de un interés o enfoque antropológico y cultural que se halla al igual en la ciencia del lenguaje que en la ciencia literaria.

Claudio Guillén subraya con énfasis la necesidad de percibir las diferencias que se presentan en lo real y de atenderlas y no mutilarlas en nuestro camino hacia el conocimiento; en este sentido argumenta a partir de textos de Fernando Savater y escribe: «¿Razón total y totalitaria? No se trata sólo de abstracciones. Todos hemos tratado a compañeros y amigos, vivas encarnaciones de la soberbia intelectual, que jamás se han cansado de imponer su monismo mental sobre el pluralismo del mundo en que vivimos, desdeñando distinciones, machacando matices, aniquilando individualidades». Por nuestra parte, creemos que, en efecto, distintas perspectivas en la investigación resultan compatibles y suponen que no se olviden no ya matices, sino componentes de lo literario: en este sentido, hemos escrito varias veces que la obra de arte existe en sí, pero no sólo en sí, es decir, que no se la puede entender monistamente. La obra poética posee determinaciones internas o inmanentes, pero a la vez existe en un momento de la serie cultural e histórica, y esto no cabe preterirlo. 
Nuestro autor se manifiesta en contra del monismo en el pensamiento crítico, y ya decimos que se encuenta totalmente en lo cierto: en tal espíritu reproduce un par de líneas del mismo Savater según las cuales «el discurso de la violencia se establece sobre un principio [...]: todo da igual, si no es lo que yo quiero». Ciertamente la experiencia de las cosas enseña que a veces se opera con esta idea de que todo es indiferente y no existe si no es lo que yo quiero, pero en el estudio lo que yo debo hacer no es lo que quiero, sino lo que me reclama el objeto atendido. Nunca hay más razón científica que la que resulta adecuada con la naturaleza o consistencia de la realidad estudiada. Lo que debe hacer el estudioso que analiza la literatura es atender a todo lo que la literatura supone como consistencia o realidad; una perspectiva puede interesarme de manera natural más que otra, para tratar unos aspectos puedo poseer mayor sensibilidad y mayor capacidad técnica que para tratar otros, pero en verdad el todo al que debo estar atento es el todo complejo en que consiste mi objeto de estudio y, por tanto, mi problema. Lo que debo analizar me viene dado ya por el objeto, y no puedo mutilarlo yo salvo a costa de perder adecuación empírica.

Forzando aparentemente el concepto, Claudio Guillén llega a proponer que las unicidades son un «caos», y en verdad así resulta: toda unilateralidad deja escapar la armonía compleja de la realidad, su vertebración matizada, y nos lleva por tanto a lo sólo parcialmente existente y parcialmente entendido, es decir, al caos de nuestro pensamiento; lo armonioso no es lo simplificado sino lo complejo. Escribe nuestro autor un amplio párrafo en este sentido: «No sostengo ni me interesa el caos de las unicidades. Lo propio de nuestra tarea es la consideración de unas moradas múltiples [...] en que brillan unos géneros, unos temas o unas formas, como también metáforas, estilos, mitos, escuelas y movimientos. Pues bien, he procurado entender esos sucesos o hechos culturales lo más posible como tendencias. [...] Cierto que un poema existe, [...] pero sí creo que desde la óptica del historiador las cosas muestran no sólo esa primera vertiente sino otra segunda, quiero decir, no sólo lo que son como substancias, como entidades suficientes, contenidas dentro de sus propios confines, sino menos visiblemente como formas, temas, mitos o movimientos que vienen de y van hacia».

Para el comparatista, los hechos literarios aparecen presididos por la dinámica temporal y espacial, y es la perspectiva que nunca debe perder: no somos sino diversos, y esa diferencia sólo no existe —sabemos 
que piensa Claudio Guillén - para la soberbia intelectual. La literatura comparada ha de hacerse cargo de lo literario en cuanto uno y diverso a la vez, $y$, asimismo, a la vez en cuanto tendencia o dinamicidad temporal y espacial, viene a proclamar nuestro autor. Glosando a Julián Marías, Claudio Guillén advierte, en efecto, que «esta función de un dinamismo [que caracteriza a la persona] puede abrirse también a ese fenómeno tan humano que no es la persona misma sino lo creado, o perseguido o soñado por ella, como proyecto y sobre todo como subproyectos, quiero decir, la acción o el hecho cultural, en su vertiente de no-cosa». Estamos ante procesos de los que el comparatista ha de hacerse cargo, de dinamicidades históricas y espacio-culturales que no deben quedar desatendidas.

Pensábamos haber dedicado una glosa a las páginas en que nuestro autor se ocupa del concepto literario de «realismo», pero ya se nos escapa el espacio y aplazamos este propósito; apuntaremos, sin embargo, que, en nuestra modesta opinión, deben tenerse presentes las páginas que al asunto dedicó Jakobson (Sobre el realismo artístico, 1921), pues tales páginas han fecundado luego otros planteamientos posteriores, y apuntaremos que de la bibliografía española sobre el realismo en tanto concepto y en tanto concreción histórica podríamos recordar asimismo varias obras de Valeriano Bozal. No hemos hecho sino saludar un nuevo libro de Claudio Guillén, y queremos aprovechar el momento para recomendar la lectura de este estudioso a nuestros alumnos: estamos ante un investigador riguroso, culto y brillante, y con planteamientos decisivos en algunos de sus trabajos. Nuestras presentes líneas no hacen justicia a su libro Múltiples moradas; por otro lado, deberá hacerse justicia al autor teniendo en cuenta no sólo este volumen reciente, sino otros capítulos de relieve que escribió y publicó hace ya bastantes años. 